\title{
ECONOMIC RATIONALITY AND ETHICAL BEHAVIOR ${ }^{1,2}$ Ethical Business between Venality and Sacrifice
}

\author{
Marc Le Menestrel \\ Department of Economics and Business \\ University Pompeu Fabra \\ Ramon Trias Fargas, 25-27, 08005 Barcelona, Spain. +34 935422723 \\ Marc.Lemenestrel@econ.upf.es

\footnotetext{
${ }^{1}$ Forthcoming in Business Ethics: A European Review.

${ }^{2}$ This paper originates from discussion with Henri-Claude de Bettignies and from my work on a model of rationality that would combine procedural and consequential dimensions. I am also grateful to the participants of the $11^{\text {th }}$ International Symposium on Ethics, Business and Society held at IESE Business School in Barcelona, July 2001.
} 


\section{ECONOMIC RATIONALITY AND ETHICAL BEHAVIOR Ethical Business between Venality and Sacrifice}

\section{Executive Summary}

This paper argues that economic rationality and ethical behavior cannot be reduced one to the other, casting doubts on the validity of formulas like "profit is ethical" or "ethics pays". In order to express ethical dilemmas as opposing economic interest with ethical concerns, we propose a model of rational behavior that combines these two irreducible dimensions in an open but not arbitrary manner.

Behaviors that are neither ethical nor profitable are considered irrational (nonarbitrariness). However, behaviors that are profitable but unethical, and behaviors that are ethical but not profitable, are all treated as rational (openness). Combining ethical concerns with economic interest, ethical business is in turn an optimal form of rationality between venality and sacrifice.

Because every one prefers to communicate that he acts ethically, ethical business remains ambiguous until some economic interest is actually sacrificed. We argue however that ethical business has an interest in demonstrating its consistency between communication and behavior by a transparent attitude. On the other hand, venal behaviors must remain confidential to hide the corresponding lack of consistency. This discursive approach based on transparency and confidentiality helps to further distinguish between ethical and unethical business behaviors.

\section{Key Words}

Rationality, Business Ethics, Economic rationality, Transparency, Confidentiality

\section{JEL}

$$
\text { A13, M14 }
$$


"He is certainly not a good citizen who does not wish to promote, by every means in his power, the welfare of the whole society of his fellow-citizens."

Adam Smith, The Theory of Moral Sentiments.

\section{Introduction}

In his famous and influential article "The social responsibility of business is to increase its profits" (1970), Milton Friedman reduces ethical behavior to economic rationality. He argues that companies allegedly promote the common good by solely pursuing their economic interest: profit is ethical.

Thirty years later, business companies have taken a prominent role in a global society. In several occasions, such as the accusations against tobacco companies' behaviors or the attitudes of oil companies towards environmental and human right issues, the social role of business has been questioned. Behind the question of whether it is business that serves society or society that is instrumentalized to serve business, there is evidence that profit may not be ethical.

In this context, how economic rationality relates to ethical behavior? Just as Friedman was reducing ethical behavior to economic rationality, a new trend reduces economic rationality to ethical behavior. Business should acknowledge a social responsibility because it is economically rational: ethics pays.

A first section of this paper argues that the reduction of economic rationality to ethical behavior and the reduction of ethical behavior to economic rationality are too simplistic, inappropriate and misleading. Considering that ethics necessarily follows from profit, or that profit necessarily follows from ethics avoids the essence of an ethical dilemma: how to rationally combine profits with ethical concerns?

This irreducibility of interest and ethical concerns is the source of our motivation for elaborating an integrated model where economic rationality and ethical behavior are distinguished and combined in a non-arbitrary manner. By recognizing that business actors can rationally answer ethical dilemmas, either in favor of interest or in favor of ethics, this paper places the ethical question beyond the one of rational behavior and emphasizes the responsibility of business actors. The interest is to provide for a simple, if not simplistic, approach to rationality that allows one to discuss ethical dilemmas explicitly and without calling one side of it "irrational".

The last section is dedicated to the potentials and limits of this approach. We discuss in particular the ambiguity proper to the revelation of ethical concerns. Because it is less specific as to its treatment of rational behavior, it is difficult to trustfully reveal ethical behavior for those who succeed in combining ethics with business interest. In the face of such ambiguity, we must go beyond behavioral approaches and adopt a more discursive approach, introducing the notions of confidentiality and transparency, in order to discriminate among unethical and ethical behaviors. 


\section{Necessity Avoids Dilemmas}

A first approach to the reduction of ethical behavior to economic rationality is to consider that being economically rational necessarily implies behaving ethically: profit is ethical. In turn, by applying a simple modus tollens argument such a statement amounts to consider that unethical behavior never pays. With such a reduction, not only it is useless to care about ethical concerns since they are automatically satisfied, but there can be no incentives to be unethical since unethical business cannot be profitable. If this were true, it would not be possible that tobacco companies behaved unethically because they have been very profitable. Similarly, it could not be unethical to target children and minorities in tobacco advertising campaigns, to subvert international authorities or to distort scientific research since these behaviors allowed considerable profits to be made (these strategies are documented and analyzed in Zeltner \& Al. 2000). If they had been unethical, then they would have been costly and because they were not, they were not unethical.

If pushed to its logical conclusions, the reduction of ethical behavior to economic rationality denies the existence of situations where economic interest and ethical concerns are conflicting. Evidently, acknowledging ethical dilemmas requires considering that it may be profitable to behave unethically. Such a consideration can however not be of any necessity in the sense that unethical behavior would be necessarily profitable. Indeed, if unethical behavior is a sufficient condition for economic rationality, then economically irrational behavior is necessarily ethical. For a business actor, it would suffice to spend money for being ethical while of course, there are many ways to be both economically irrational and unethical. A costly behavior may be unethical and must be distinguished from one that is ethical. Should we maintain the possibility of acting both unethically and unprofitably, one couldn't consider that forgiving profits is a guarantee of being ethical.

It is striking how reductionist arguments appear to deny the peculiarity of the relation between economic interest and ethical concerns. Another typical reduction consists in considering that only behaviors that are costly are truly ethical. In other words, ethical behavior would be necessarily costly. But then, economically rational behavior would be necessarily unethical. This indeed would contradict the statement that profit is ethical. If a behavior is profitable, then it is ethical. But if it is ethical then it is costly and if it is costly, then it is not profitable. Within this reductionist approach, there is a contradiction in arguing at the same time that profit is ethical and that ethical behavior must be costly (see Friedman 1971: 219 for such a self-contradicting example). Considering that ethical behavior is necessarily costly also deprives business of any incentive for being ethical. For example, if it is ethical to refrain from polluting the environment, then it is not possible to make profits by implementing an efficient program of emission reductions or by re-orienting activities towards forms of energy production that pollute less than oil. But the management of environmental and social issues is not purely a cost. There can be important long-term strategic benefits to a proactive approach to these issues (for an example, see Moser, 2001). Business can invest in ethics in an attempt to combine it with economic interest: there is no necessary contradiction between ethics and profits.

One may push further such reasoning and consider that ethics pays. In that case, it is economic rationality that is then reduced to ethical behavior. Like considering that profit is necessarily ethical, such a reduction may seem attractive at first glance. It provides a simple argument to motivate business: ethics become instrumental, being 
reduced to a means towards economic rationality, like one positive attribute that business should now consider within its role. But we should be aware that such a reduction couldn't be of necessity. If ethics necessarily pays, then costly behavior is necessarily unethical. There is no place for sacrifice in this approach. There is no dilemma between a willingness to do the good and an interest in not doing so. For example, if business wants to be ethical, it should never pay for it by choosing a costly behavior, because such a behavior would be necessarily unethical. By reducing economic rationality to ethical behavior, we provide for a reasoning according to which no economic sacrifice may be ethical and thus justified. Once again, the very tension of an ethical dilemma is ignored.

From profit is ethical to ethics is profitable, the four implications we have studied may be summarized in the Table 1, contrasted by their equivalent but unreasonable counterpart.

Table 1: Unreasonable Reductions

\begin{tabular}{ll}
\multicolumn{1}{c}{ POSSIBLE R EDUCTION } & EQUIVALENT STATEMENT \\
\hline Profit is necessarily ethical & Unethical behavior never pays \\
Ethics is necessarily costly & Profit is always unethical \\
Unethical behavior is necessarily profitable & Costly behavior is always ethical \\
Ethics is necessarily profitable & Costly behavior is always unethical \\
\hline
\end{tabular}

Although it is tempting to avoid ethical dilemmas by stating that profit is necessarily ethical, to justify a course in ethics by stating that unethical behavior is necessarily costly or to motivate ethical behavior by stating that ethics pays, these arguments should be considered with care. If pushed to their structural validity, they become unreasonable and fail to capture the dilemmas between economic rationality and ethical behavior.

Business does face situations in which no behavior is both economically rational and ethical. In these situations, it is certainly not sufficient to consider that making profit is necessarily ethical or that being ethical will be necessarily profitable. The responsibility of such a choice rests within the subject who carries it, not in an abstract form of reasoning that would lead to a definitive and a priori true answer. In the words of Kaler (1999: 209), such approaches are too specific. Rather than reducing one to the other, business interest and ethical concerns should first be considered irreducible in order to approach their combination rationally. In this manner, the acknowledgment of the irreducibility of economic interest and ethical concerns is a first step towards a methodological approach to ethical dilemmas.

\section{Rational Ethical Dilemmas}

If an economically rational behavior is not necessarily ethical and if an ethical behavior is not necessarily economically rational, then there are unethical behaviors that are economically rational and there are ethical behavior that are not economically 
rational. Because such behaviors embody an irreducible tension between ethical concerns and economic interest, they reflect ethical dilemmas. An ethical dilemma occurs when one has to choose a behavior where economic interest and ethical concerns conflict.

There are thus two types of behaviors in the face of ethical dilemmas: one where economic interest is sacrificed to the respect of ethical concerns, the other where ethical concerns are ignored so that economic interests are maximized. Which one of them is rational?

It has been a constant trend of economic methodology to argue that there is one and only one form of rationality: economic rationality. In this perspective, the sacrifice of economic interest for the sake of ethical concerns is irrational. A typical example of such an approach in the case of environmental issues is the position taken by Velasquez (1992) when he explains why it is "irrational" for a multinational company to choose to refrain from polluting the environment.

Because such a perspective denies any rationality to immaterial concerns, it is often qualified as pragmatic. A pragmatic approach to rationality ignores ethical dilemmas by not considering the possibility of a rational sacrifice. One should do what he desires. Such an approach is justified by a consequential reasoning, tightly related to the utilitarian doctrine. In the words of one of its founder: "Of two pleasures, if there be one to which all or almost all who have experience of both give a decided preference, irrespective of any feeling of moral obligation to prefer it, that is the more desirable pleasure" (J.S. Mill 1991: 139).

It is not our goal to discuss philosophical doctrines but to push to the extreme the reduction they underlie so as to justify an integrated approach. In such consequential approach, any rational behavior is guided by some expectations of consequences. These consequences differ by their interest and rational behavior is the choice of the behavior that leads to the best consequence. In this manner, rational behavior is reduced to the pursuit of interest and behaviors that are not motivated by interest are irrational. In theory, what is of interest is left undefined, so we can always find an informal argument that reduces any type of motivation to some interest newly defined. In practice, and Friedman at least was explicit about it, interest is actually reduced to money, which becomes the common measure of all economic rational behaviors. Once again, the irreducible tension between economic interest and ethics is hidden.

An idealist perspective classically contrasts the pragmatic one. It considers that ethical concerns should never be compromised to the pursuit of interest. What is rational to do is what is right to do, and there is no right to be unethical. Unethical behaviors that are economically rational are thus irrational while sacrificing economic interest for an ethical concern is necessarily the rational behavior. This perspective is best exemplified by Kant's doctrine of pure ethics. In his words, there is no right to lie, in practice and in theory (e.g. Kant 1993) ${ }^{3}$.

Such an approach hasn't been empirically supported by the economic development of the $20 \mathrm{e}$ century. Remember the declaration of Tobacco industry top executives

\footnotetext{
${ }^{3}$ Neither Kant nor Mill approaches towards ethical dilemmas should be reduced to such oversimplified statements. Indeed, we believe such reductions reflect more the interest of the commentators than the writings of their authors (see e.g. Louden 2000 for a very innovative to Kant's doctrine). This is also the sense of our quote from Adam Smith at the beginning of the paper.
} 
affirming in front of the U.S. Congress that tobacco is not addictive. There may be no rational right to lie but some individuals and some businesses do rationally engage in unethical behavior. Each occurrence of an unethical behavior rationally chosen for the pursuit of interest is an empirical invalidation of the reduction of rationality to ethical behavior. By denying rationality to unethical behavior, the idealist perspective departs from empirical observation of actual phenomena. The argument that unethical behavior is irrational, built on the preeminence of ethics over interest has thus failed to convince in practice.

If neither the pragmatic nor the idealist perspectives provide us with a convincing answer to the question of rational behavior in the face of ethical dilemmas, we may try to combine both in a third way. More precisely, we may suppose that it can be rational to choose a profitable but unethical behavior as well as to choose a costly but ethical behavior. Rationality does not appear as a criterion to solve ethical dilemmas and whether a particular business sacrifices its interest or violates its ethical principles depends on its moral values and the interests at stake, not on whether it is rational or not. This reflects that the freedom of choice in the presence of ethical dilemmas is beyond rationality, neither idealism not pragmatic being able to determine it alone. It reflects a focus on the specific tension between the two types of approaches while in pragmatic and idealist approaches, such a tension is reduced to one dimension. Such a stance is beautifully exemplified by this teaching of Vivekananda (1988: 276):

\section{"Materialism says, the voice of freedom is a delusion. Idealism says, the voice that tells of bondage is delusion. Vedanta says, you are free and not free at the same time; never free on the earthly plane, but ever free on the spiritual."}

One integrated approach to combine explicitly material and ethical concerns considers that any behavior is composed of a process and a consequence. Evaluation of behavior in terms of the consequences for the actor corresponds to the pragmatic approach. To each consequence is assigned a quantity that represents its desirability. Besides, appreciation of behavior in terms of processes, as means to reach consequences, corresponds to the idealist approach. Means are appreciated qualitatively depending on whether they respect or violate ethical principles. Depending on whether one wants to look at consequences only, at processes only, or at the combination of both, one can approach rationality in a pragmatic manner, in an idealist manner, or in an integrated manner. In the last case, the ends do not necessarily justify the means but the means does not justify the ends either ${ }^{4}$.

Naturally, in such an integrated approach, there exists a type of behavior that combines ethics and interest. We call optimal a rational behavior that is both ethical

\footnotetext{
${ }^{4}$ This duality of rational behavior is present in many forms in the literature. It has however been overshadowed by the development of quantitative approaches to rationality where mathematical models reduce everything to one single type of elementary concerns (see e.g. Weber 1978: 24-26, Simon 1978, Frank 1988). It is puzzling to realize that researchers are reluctant to consider mathematical models distinguishing explicitly processes from consequences. Sen (e.g. 1987: 74), for instance, argues for a consequential approach where consequences are "comprehensively" defined, i.e. including procedural considerations. Le Menestrel (1999) supposes there exist specific preferences for the process by which consequences are reached and considers the case where process preferences "do not matter" as a limit case.
} 
and economically rational. By combining the two types of motivations, interest and ethical concerns, optimal behavior is "harmonious". When possible, we consider it irrational not to choose the right means to attain the best end. In other words, an optimal behavior is always rational. Conversely, a rational behavior is not necessarily optimal since an ethical dilemma may oppose ethical concerns with economic interest.

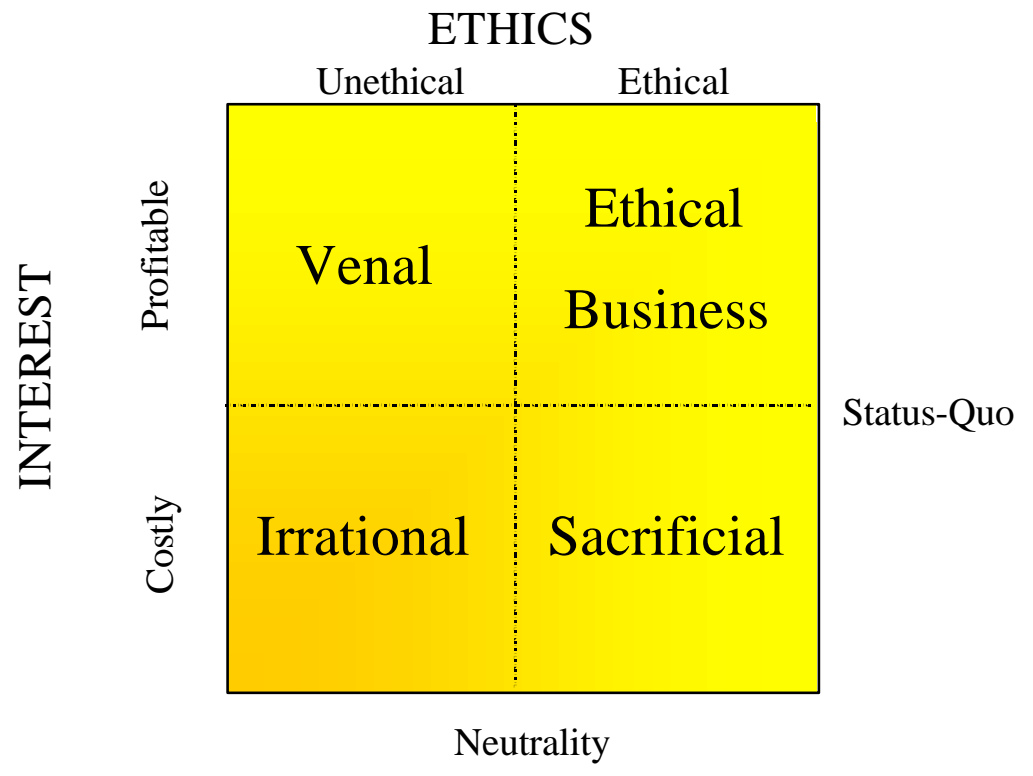

Figure 1: Ethical Business between Venality and Sacrifice

We thus consider that behaviors that sacrifice economic interest for ethical concerns or violate ethical principles for the pursuit of interest are rational. Irrational behaviors are restricted to behaviors that are both unethical and economically irrational. In Figure 1, we call venal and sacrificial the two types of behavior in the face of ethical dilemmas. so as to emphasize their lack of optimality with regards to ethical concerns and economic interests. Ethical business, when economic interest meets with ethical concerns, lies between venality and sacrifice.

Building on the irreducibility of ethical concerns and economic interest, we have proposed an approach to rationality that combines these two types of motivations without giving priority to one or the other. It treats as rational some behaviors that would be irrational in a reductionist approach to rationality, either idealist or pragmatic. In the next section, we show how this helps to better understand the distinctions among different rational behaviors.

\section{The Ambiguity of Ethical Business}

If a venal behavior, a sacrificial behavior, and an optimal behavior may all be rational, how is it possible to distinguish among these forms of rationality by observing the behavior of actors? If, in particular, we suppose that the behavior of a business actor is rational, can we infer whether such a behavior is ethical or unethical?

Answering such questions depends on what we may be able to observe and measure about behavior. In this respect, judgments of ethical nature differ from judgments about economic interest. As we said, there are indeed two different types of judgements involved in the characterization of our integrated approach to rational 
behavior. There are judgements on the consequences, which refer to the maximization of a quantity (e.g. money), and judgements on the process, which refer to some qualitative criteria (e.g. ethical principles). Business actors treat economic interest in an objective and explicit manner and the profitability of a business, at least a posteriori, aims at constituting an objective quantitative measure. This leads us to consider that we are able to observe whether a behavior is profitable or not. However, the measure of ethical concerns is bound to remain dependent upon the ethical principles called for justifying a particular behavior. We thus do not assume that we can observe directly whether a behavior is ethical or not.

Suppose first that one observes a behavior that is not profitable. If the behavior is considered rational, then it implies it is also ethical. This is simply because if it was unethical, then it would be irrational. In this manner, engaging in non-profitable behavior reveals that the company as acted according to some ethical concerns. In this manner, sacrificial behaviors can be distinguished by assuming rational behavior.

Suppose now that we observe a profitable behavior. Then, we cannot infer whether this behavior is ethical or not by simply supposing this behavior is rational. A rational and profitable behavior may be ethical or unethical depending on the ethical values of the actor and the interests at stake. A business actor may engage in unethical behavior because no optimal behavior is available and because he places its economic interest before its ethical concerns. In this sense, it is not sufficient to assume the rationality of the actor to reveal ethical concerns when one observes a profitable behavior. Since assuming rationality is sufficient to reveal ethical concerns when one observes a behavior that is not profitable, this approach to rationality is informative in the absence of profitability but remains ambiguous in the presence of profitability. If it is not necessary to be economically irrational to be ethical, it is however necessary to be so in order to let others know you are ethical.

This may be helpful to understand, for example, the conflict between environmentalist activists and some successful oil companies who, possibly, make real efforts to integrate ethical concerns in their behavior. Because oil companies are all very profitable, it is not possible to infer whether they are really ethical or not. This ambiguity creates a difficulty for ethical business to distinguish itself from venal business in a credible manner.

It is the behavioral character of our approach to rationality that does not allow us to discriminate between venal and optimal behavior. If one wants to capture ethical concerns in these cases, one also must consider the level of intentions, even though these intentions may not necessarily have behavioral consequences. Beyond behavior itself, intentions may be revealed through the argumentation and justifications of rational behavior. Such an approach assumes that attitudes towards communication differ depending on whether one has the intention to act ethically or not (Habermas 1992).

Consider a rational business actor who engages in a venal behavior. His rational choice for such a behavior is justified by its consideration of economic interest before ethical concerns. But it is very difficult to avow such justification through a socially acceptable argumentation. Imagine a Tobacco company stating that, they do all what is in their power to make more profit, never compromising such profit for ethical considerations. Such a cynical attitude, if possible in the facts, would still not be accepted as a socially legitimate discourse. Similarly, some oil companies fiercely opposing mandatory restrictions on their $\mathrm{CO}_{2}$ emissions in the fear of decreasing their 
profits do not say bluntly that they act as such just to make more profits. Business actors engaging in venal behaviors are thus inclined to adopt an argumentation where their behavior appears more ethical than it is. In this sense, their communication may not be consistent with the actual ethical character of their behavior.

On the other hand, a rational business actor who engages in an ethical behavior, either optimal or sacrificial, has no reasons not to justify its behavior by its ethical considerations. Moreover, rendering these justifications more prominent may constitute a social advantage that can increase the economic interest of the ethical behavior. Consider for instance a tobacco company that intends to engage in combating advertising to children. If such a behavior implies a loss in terms of profitability, it will tend to alleviate such a loss by using their ethical commitment as an additional means to economic profitability by distinguishing itself from competitors. Similarly, consider an oil company that intends to engage in constraining its fossil emissions. Even if this behavior is optimal and thus could also be justified in terms of economic interest, there is no reason not to also capitalize on the ethical dimension of this behavior by communicating upon it. Business actors engaging in sacrificial and optimal behaviors are inclined to adopt an argumentation that highlights the ethical character of their behavior. In this case, their communication tends to be consistent with the actual ethical character of their behavior.

As we can see, the consistency between communication and behavior appears as a criterion to distinguish between venal and optimal behavior, between what one says and what one does. When a behavior is profitable but unethical, such consistency raises difficulties because a cynical argumentation lacks social legitimacy. Business actors may thus not say what they really do. When a behavior is profitable and ethical, such consistency becomes a means towards social legitimacy and additional economic consequences. In this case, business actors may rather say what they really do, even though they may not do it for the justifications they give.

These attitudes towards communication imply distinctive managerial approaches of the relation with society. In the case of venal behaviors, there is a need to protect one's business interests by ensuring the confidentiality of the unethical dimensions of behavior. In the case of ethical business or sacrificial behavior, there is an interest in ensuring the transparency of the ethical dimensions of behavior. The former would correspond to a competitive attitude towards society while the latter would correspond to a cooperative attitude towards society. To the extent these managerial attitudes are themselves observable, they provide for an indirect revelation of the ethical nature of the underlying behaviors. Business actors engaging in venal behavior will tend to adopt competitive attitudes relayed by a strict confidentiality of their actual behaviors, in order to hide that these behaviors are not consistent with their communication. Business actors engaging in ethical behavior, sacrificial or optimal, will tend to adopt cooperative attitudes relayed by an increasing transparency of their actual behaviors, in order to demonstrate that these behavior are consistent with their communication (see Figure 2). 


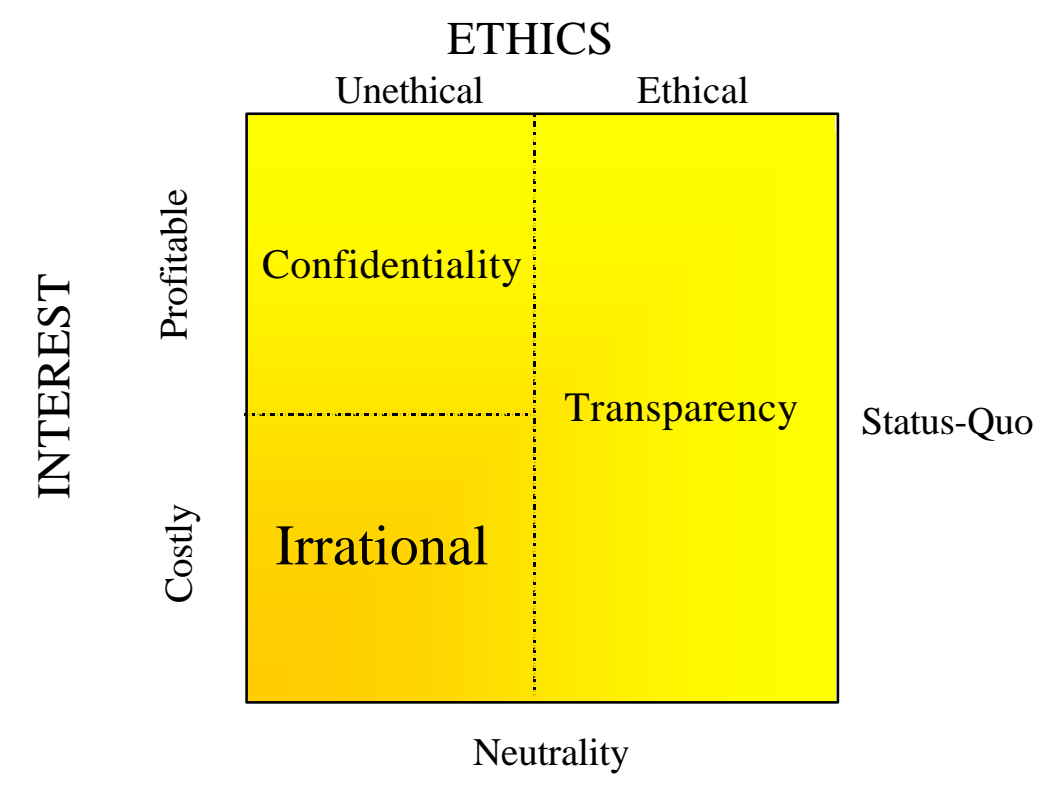

Figure 2 : Confidentiality and Transparency Towards Society

As an example, one may distinguish between the attitudes of different oil companies. All companies are very profitable at the moment and the ambiguity is whether some adopt more ethical behaviors than others. For instance, the confidentiality that has surrounded one of their most important lobbying force: the Global Climate Coalition, is an indication in itself of the desire to render difficult the establishment of a correspondence between behavior and communication. Typically, the list of members of such groups is not publicly available. That Exxon was a leading business actor behind it has remained more or less hidden to the general public. In light of our approach, these render suspect their behavior and provide for an indication, if not a proof, that they are indeed ignoring ethical concerns so as to maximize their economic interest. In turn, the now systematic attendance of some other oil companies in open forums about climate change, their increasing call for participatory approaches, and their reference to an ideal of unanimity are indications that they are ready to acknowledge ethical concerns and intend to act ethically. Those companies will thus have to take their distance from lobbying groups that act confidentially. As BP Amoco, Shell and others have done, they indeed do so with strong and widespread communication on their ethical stance (a detailed and documented analysis of the case of oil industry and climate change can be found in van den Hove \& Al. 2001). As we said, it is only when they will sacrifice some economic interest for their ethical concerns that they can ascertain their good faith. In the absence of such economic sacrifices, we can only hope that communicating about their ethical stance and engaging in more transparent attitudes reinforces the likelihood of unethical behaviors to be reported and thus reinforces their propensity to do what they say.

To summarize, we have shown that a behavioral approach to rationality that combines ethical concerns and economic interest allows ethical concerns to be publicly revealed in case of sacrificial behavior but remains ambiguous as whether a profitable behavior is ethical or not. We have thus proposed to consider acts of communication in order to reveal ethical concerns. We proposed that venal behaviors might be indirectly revealed by competitive attitude towards society based on confidentiality of the behaviors. The idea is to prevent the society from knowing how profitable 
consequences are attained. Optimal behaviors might in turn be revealed by cooperative attitudes towards society based on transparency. The objective is to allow society to observe how profitable consequences are attained.

\section{Conclusion}

In this paper, we start by considering that a better rational integration of economic and ethical dimensions could be helpful to better understand social behavior of business actors. We think that such integration is difficult to realize because reductionist approaches are too simplistic to capture the type of combination and of trade-off between economic rationality and ethical behavior. The considerations that ethics is necessarily costly, that profit is necessarily ethical, that a lack of ethics pays, or that ethics necessarily pays fail to capture common sense as well as observation of the business world.

We propose to acknowledge the irreducibility of these two types of considerations so as to distinguish different types of rationality, beyond idealist and pragmatic approaches. We have referred to optimal behavior to characterize a profitable and ethical behavior, to venal behavior for one that is profitable but unethical, and to sacrificial behavior for one that is ethical but not profitable. Not all behaviors are nevertheless rational since a behavior that is unethical and not profitable is considered irrational. Such approach introduces a form of relativism in rationality because the choice between a venal and a sacrificial behavior is not rationally determined but relative to the values of the actors and the interest at stake. We have argued that such an integrated approach is however not arbitrary since it helps to reveal unethical behavior when a rational actor chooses an ethical but not profitable behavior. We also insisted on a remaining ambiguity to discriminate between profitable behaviors.

In our view, these limitations are due to our behavioral approach to rationality and we have thus attempted to introduce an analysis of communication to enhance our understanding of ethical dilemmas. Because every one prefers to communicate that he acts ethically, ethical profitable behavior can be distinguished from profitable unethical behaviors by the transparent and confidential attitudes they respectively imply. In this manner, we complemented a behavioral approach with a discursive one.

\section{References}

Frank, R. 1988. Passions within Reason. New York: Norton.

Friedman, M. 1970. 'The Social Responsibility of Business is to increase its Profit'. New York Time Magazine, September 13.

Habermas, J. 1992. Moral Consciousness and Communicative Action (Studies in Contemporary German Social Thought). Boston MA: MIT Press.

Kaler, J. 1999. 'What's the good of ethical theory?'. Business Ethics: A European Review, 8:4, 206-213.

Kant, I. 1993. Grounding for the Metaphysics of Morals : With on a Supposed Right to Lie Because of Philanthropic Concerns. Hackett Pub Co.

Le Menestrel M. 1999. 'A Model of Rational Behavior Combining Processes and Consequences'. Unpublished Dissertation Thesis, INSEAD. 
Louden, R.B. 2000. Kant's Impure Ethics: From Rational Beings to Human Beings. New York \& Oxford: Oxford University Press.

Mill, J.S. 1991. On Liberty and other essays. Oxford: Oford World's Classic.

Moser, T.: 2001. 'MNCs and Sustainable Business Practice: The Case of the Colombian and Peruvian petroleum Industries'. Forthcoming in World Development.

Sen, A. 1987. On Ethics \& Economics. Oxford: Blackwell Publishers Inc.

Simon, H.A. 1978. 'Rationality as Process and as Product of Thought'. The American Economic Review, 68, 1-16.

van den Hove, S., Le Menestrel, M., de Bettignies, H-C. 2001. 'The Oil Industry and Climate Change: Strategies and Ethical Dilemmas'. Submitted to Climate Policy.

Velasquez, 1992. International Business, Morality and the Common Good'. Business Ethics Quarterly, 2, 1, 27-40.

Vivekananda, S. 1998. Teachings. Calcutta: Advaita Ashrama.

Weber, M. 1978. Economy and Society: An Outline of Interpretive Sociology. Berkeley: University of California Press.

Zeltner T., Kessler D., Martiny A., Randera F. 2000. 'Tobacco Company Strategies to Undermine Tobacco Control Activities at the World Health Organization', Report of the Committee of Experts on Tobacco Industry Documents. World Health Organization. Available at: http://filestore.who.int/ who/home/tobacco/tobacco.pdf. 